\title{
Mapping Population Dynamics at Local Scales Using Spatial Networks
}

\author{
José Balsa-Barreiro $\mathbb{D}^{1,2}$ Alfredo J. Morales $\mathbb{D}^{1},{ }^{1}$ and Rubén C. Lois-González $\mathbb{D}^{1,2}$ \\ ${ }^{1}$ Human Dynamics, MIT Media Lab, Massachusetts Institute of Technology, Cambridge, MA 02139, USA \\ ${ }^{2}$ ANTE Research Group, Galician Studies and Development Institute (IDEGA), Santiago de Compostela 15782, Spain \\ Correspondence should be addressed to José Balsa-Barreiro; jobalbar@gmail.com
}

Received 14 July 2020; Revised 1 October 2020; Accepted 25 March 2021; Published 31 May 2021

Academic Editor: Ãtila Bueno

Copyright ( $) 2021$ José Balsa-Barreiro et al. This is an open access article distributed under the Creative Commons Attribution License, which permits unrestricted use, distribution, and reproduction in any medium, provided the original work is properly cited.

\begin{abstract}
Nowadays, around half of the global population lives in urban areas. This rate is expected to increase up to two-thirds by the year 2050. Most studies analyze urban dynamics in wide geographic ranges, focusing mainly on cities. According to them, the global population is spatially distributed (and polarized) in two extremes: large urban agglomerations and rural deserts. However, this remark is excessively general and imprecise. For this reason, it remains essential to analyze these dynamics at other spatial scales. A close-up look in thinly populated regions shows how urban dynamics are also noticeable. In this paper, we analyze spatiotemporal patterns of population distribution in a predominantly rural area by applying a local-scale approach. These patterns are represented by using spatial networks with nodes representing the human settlements and links showing hierarchies between nodes. This case study is conducted in a small municipality located in northwestern Spain. It is a predominantly rural area with a very particular spatial pattern of population distribution.
\end{abstract}

\section{Introduction}

The global population is increasingly concentrated in urban areas. According to United Nations (UN), more than 4 billion people live nowadays in urban areas, which represent 55.2 percent of the global population [1]. The most eyecatching aspect related to urbanization is the continuous growth in recent decades. In 1960, only 33.6 percent of the global population was living in cities, 21.6 percent less than today. This same trend towards urbanization will continue in the upcoming years. Recent UN projections forecast that the rate of urban population is expected to be more than twothirds by 2050 .

The spatial pattern of the global population is increasingly polarized. Large megalopolises with millions of inhabitants coexist with immense empty spaces. These spatial inequalities are apparent from different perspectives. Territorially, around 50 percent of the global population is currently concentrated in just around one percent of the planet's surface [2]. Over time, developing countries are under a more strong urbanization process compared to developed countries in the past. It favors the emergence of overurbanization processes in these countries showing rates of urban population considerably larger than expected for their levels of economic development and wealth concentration $[3,4]$.

In the past, people have mostly lived in very low-density rural settings. In 2007, the rate of urban population at a global scale exceeded 50 percent by showing how the major relevance of urban dynamics is relatively recent. It is particularly notorious in the last two centuries with the emergence of the industrial revolution. Over time, the urbanization process experienced by western countries was relatively slow in line with the emergence of industrial activities and wealth concentration in cities. In consequence, people from rural areas migrated to cities where the most of labor opportunities were concentrated. Nowadays, developing countries located in East Asia and Africa experience a very rapid increase in urbanization rates [5]. Conversely, the generalized lack of future job opportunities in rural areas explains the massive migration to cities. Thus, the population flows that developed countries experienced in the 
last two centuries are being replicated nowadays in developing countries, but more rapidly. It explains the exponential growth rates experienced in large cities located in developing countries without adequate infrastructures to support their urban growth. The emergence of pseudourbanization or false-urbanization processes [6,7] helps to understand the majority of negative dynamics related to these areas in terms of poverty, marginality, social deprivation, and increasing violence rates. At a global scale, traces drawn by the centers of gravity related to relevant sociodemographic indicators show this trend. In Balsa-Barreiro et al. [8], it is observed how the global wealth is moving towards the global East, while traces related to the increase of population and urbanization rates are shifting to the global South.

Cities concentrate people, goods, means of production, and services. These offer great benefits due to the proximity between labor opportunities and potential workforce, which allow them to reduce transportation costs and to reach a more efficient use of resources, among other benefits. Urban regions favor a larger and more flexible labor market, where companies find a vast reservoir of the workforce and where workers can find a great number of employment opportunities. The proximity between both agents within urban areas allows to increase labor productivity and to boost the potential exchange of knowledge and ideas [9]. For these reasons, population and wealth are likely to grow at once within cities [10], which helps to understand why the richest countries are urban economies [11]. However, the relationship between urban population and wealth is not strictly linear. Dobbs and Remes [12] analyzed the quantitative weight of the 2,600 largest global cities. These cities concentrated 38 percent of the global population, but 72 percent of global GDP. This study evidences the emergence of enormous inequalities between cities and regions on a global scale [13].

The attractiveness of cities and rapid urbanization step up conflicts related to aspects such as gentrification, social segregation and polarization, pollution, and mobility. An example related to their environmental impact is as follows: cities account nowadays for more than 70 percent of global greenhouse-gas emissions and city dwellers generate more than 2 billion tons of waste per year, a rate that is expected to increase to 3.40 billion tons by 2050 [14]. In this sense, experts warn about the emergence of the so-called urban diseconomies which refer to a bunch of negative externalities derived from constrained mobility, the poor accessibility between districts in terms of travel-times, the predatory living costs, and/or the excessive employment competitiveness in cities, among other factors [15-17].

Positive and negative externalities related to urbanization are distributed across the territory in an unbalanced way. Although the vast majority of the world is nonurban, it becomes more dependent on cities than ever. Cities are always dependent on external resources in terms of land, water, energy, and food, among others. These demands increase the pressure on agrarian and forestry lands surrounding cities, overloading natural landscapes and leading to forced changes in land uses. A well-established example is shown in the repeated emergence of intentional wildfires in areas surrounding many south European cities [18, 19].

In response to this, experts and policy authorities must offer solutions according to the principles of sustainable development, territorial convergence, and social cohesion. Thus, all people should have access to the same labor opportunities, irrespective of their place of origin. Strongly encouraged by this statement, the New Urban Agenda adopted by the UN at the Habitat III conference [20] was exclusively focused on the power of cities as driving forces for sustainable development at a global scale.

On this basis, a comprehensive perspective of the entire territory beyond the cities is still lacking. One essential issue refers to the multiscalability of urbanization processes, an aspect that is addressed in this paper. Our objective here is to identify urban patterns in territories that are not properly cities by using a local-based approach. For this purpose, we analyze the spatial variability in population flows in a small Spanish municipality in a dataset covering an extensive time period, starting in the late 19th century.

The remainder of this paper is organized as follows. In Section 2, we contextualize the study area presenting its main geographical aspects. In Section 3, we explain the methodology used for mapping spatial networks. In Section 4, we conduct a multiscale analysis of the population change in our study area since the late 19th century. Results are shown in charts and spatial networks depending on the spatial scale and data aggregation. These results are discussed subsequently in Section 5. Finally, we close with the conclusions of the study where the most relevant aspects are summarized.

\section{Study Area}

The study area corresponds to a small municipality located in Galicia, in northwestern Spain (Figure 1). The municipality of Santa Comba has 9,635 inhabitants distributed in 203 square kilometers [21]. Its population density is 47.5 inhabitants per square kilometer, which is around half compared to its region (92 inhabitants). Its main town, named identically as the municipality, is the most populated settlement counting 28.3 percent of the total population (2,731 inhabitants in 2015). According to Goerlich et al. $[22,23]$, it would be an eminently rural municipality, without a single human settlement exceeding 5,000 inhabitants. This accords with the methodology employed by Eurostat, which considers eminently rural municipalities with a population density lower than 100 inhabitants per square kilometer [24]. On the one hand, according to Zoido and Arroyo [25], this municipality is at the intermediate interval between rural and urban, with a population lower than 10,000 inhabitants.

The region of Galicia, where the study area is located, presents a particular spatial pattern of population distribution. Traditionally, this spatial pattern was characterized by high fragmentation and dissemination across the entire territory. This region concentrates nearly 50 percent of all the singular population entities located in Spain. In comparison, this rate is about 10 times larger than its demographic weight at a national level [21]. The municipality of Santa Comba is 


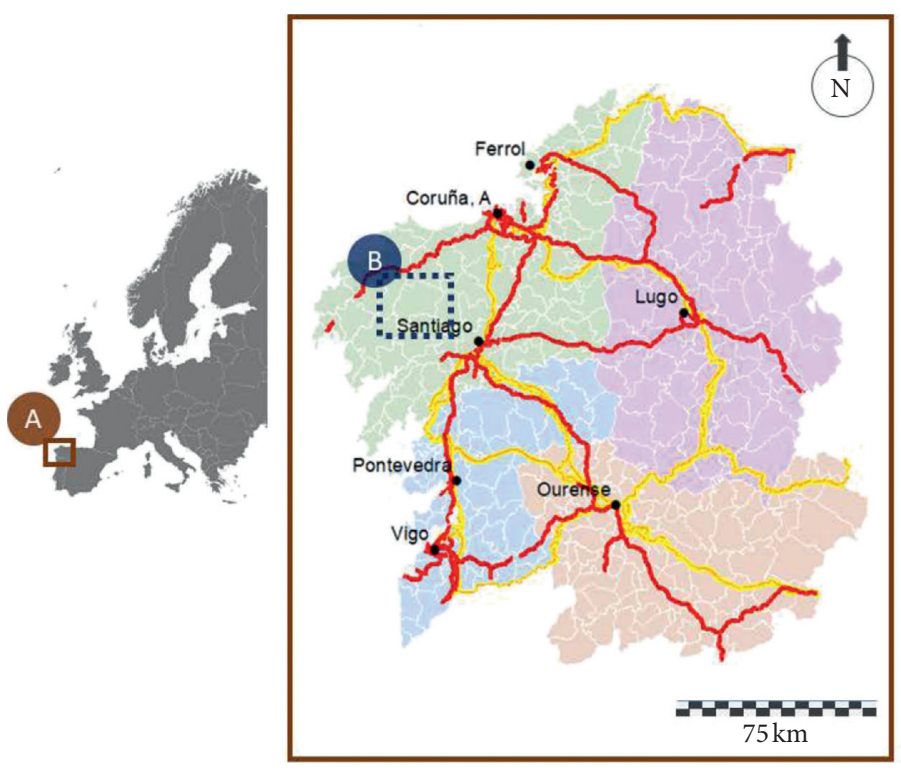

(a)

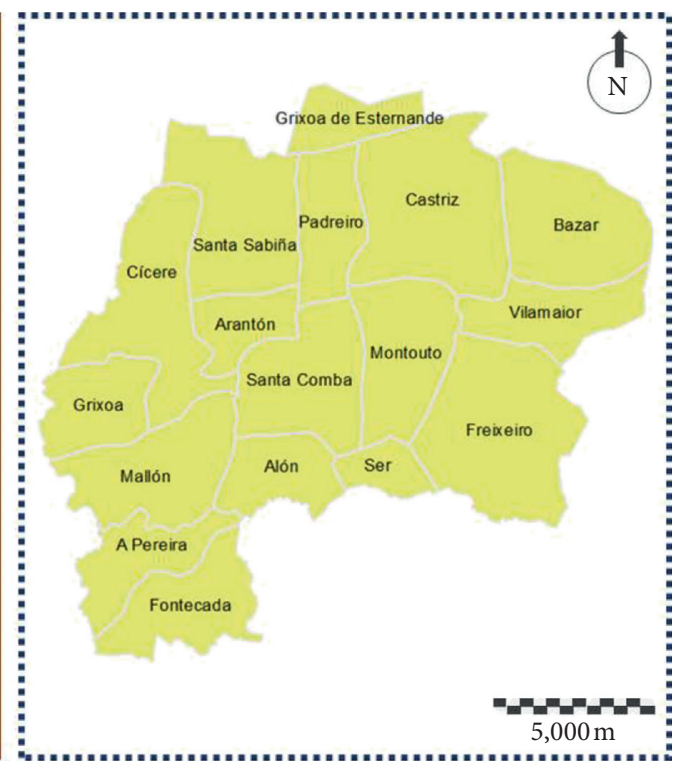

(b)

FIgURE 1: Location of the study area. The municipality of Santa Comba is located in the northwestern sector of the region of Galicia, Spain. In the box $(A)$, the black-labeled nodes correspond to the most populated cities, whereas the indicated lines show the most important road infrastructures. High-capacity roads are displayed in red color and railways in yellow. In box $(B)$, the distribution in parishes within the study area is shown. (a) Zoom $A$. (b) Zoom $B$.

located next to the so-called Atlantic Axis, the area where the major and most thriving cities within the whole region are located. However, despite its geographical closeness, this municipality decreases its population over a long period showing a similar behavior like the surrounding area located on the west side: the so-called Costa da Morte [26, 27].

Like the entire region, the internal distribution in parishes within our particular study area presents a great significance to fully understand its territorial structure nowadays (Figure 1). The parish is a territorial figure with an ecclesiastic origin and without any official administrative competence. However, it constitutes an essential figure for understanding social and power relationships between people, especially in rural areas. This figure is the key to understand the topology and evolution of the spatial pattern of population distribution within this region.

Within our particular study area, a total of 175 human settlements distributed across 17 parishes were registered by official population censuses published since the late 19th century. Some of these settlements were eventual because they emerged and/or faded away sporadically in just some of the censuses.

Population data were collected for the period from 1888 to 2015. These data were extracted from the Nomenclator de Población, an official census published by the Spanish Statistical Office [28]. Albeit with some exceptions, this dataset is published every ten years.

\section{Methodology}

In this paper, we analyze the internal population flows in a rural area covering an extensive time period, starting from the late 19th century. Spatial networks are implemented for mapping these flows. These spatial networks consist of nodes and links. The nodes represent human settlements and these are located according to their spatial coordinates. The links connect the nodes according to a two-folded hierarchical criterion: territorial dependence and total population.

The implementation of these spatial networks is shown graphically in Figure 2. The most populated human settlement of the entire municipality determines the main node, which is shown in Figure 2(a). This node is the central hub for a firstorder network, where this main node connects with the most populated settlement in each parish. In total, 17 nodes and 16 links compose this first-order network, which is shown in Figure 2(b). A second-order network is implemented for each parish. This network connects the most populated settlement in each parish with all the other settlements within this same parish. Thus, a bunch of 17 individual minor networks is implemented. These second-order networks are shown in Figure 2(c). Finally, the entire spatial network results from merging the first-order network and all the independent second-order networks (Figure 2(d)). All the human settlements officially reported since the late 19th century are included in this comprehensive spatial network.

The topology of the spatial network shown in Figure 2 is adapted to one particular year, that is, in this case, 2015. This topology varies depending on the population data in each census year. Thus, the most populated settlement in the whole municipality determines the topology of the firstorder network. The most populated settlement in each parish not only determines the topology of the different secondorder networks but also defines partially the topology of the first-order network at its edges. Similarly, the number of nodes depends on the total number of settlements officially reported in one particular census year. 


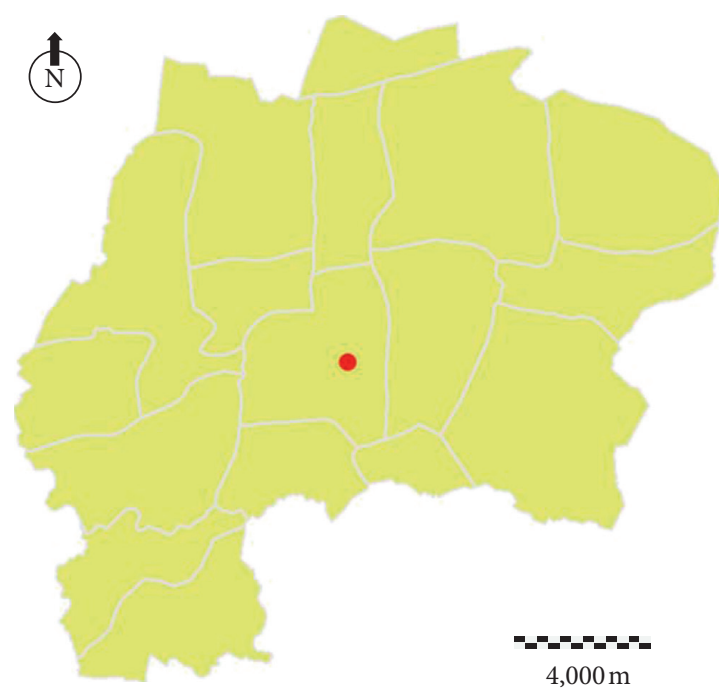

(a)

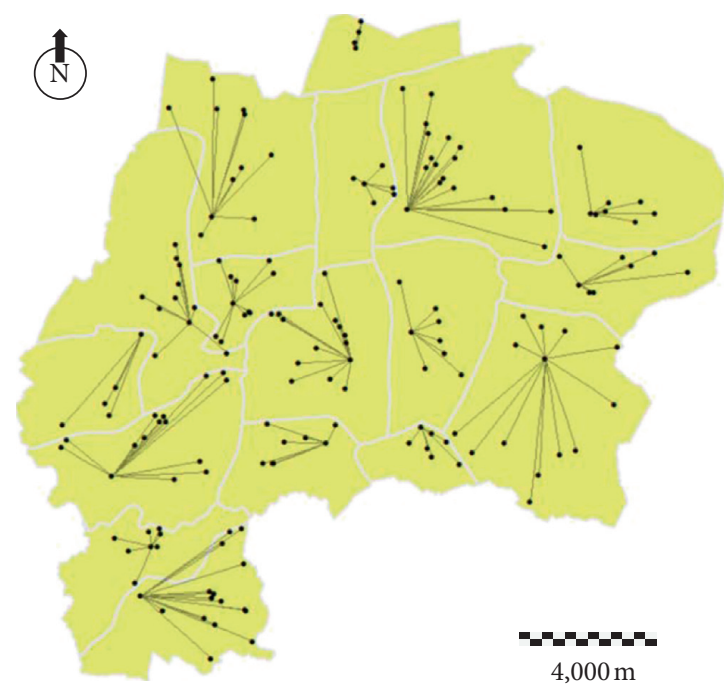

(c)

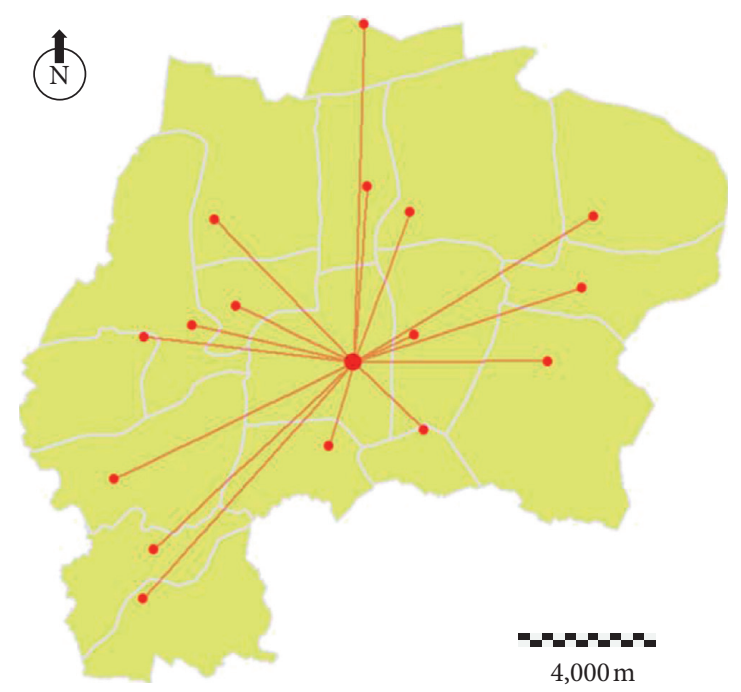

(b)

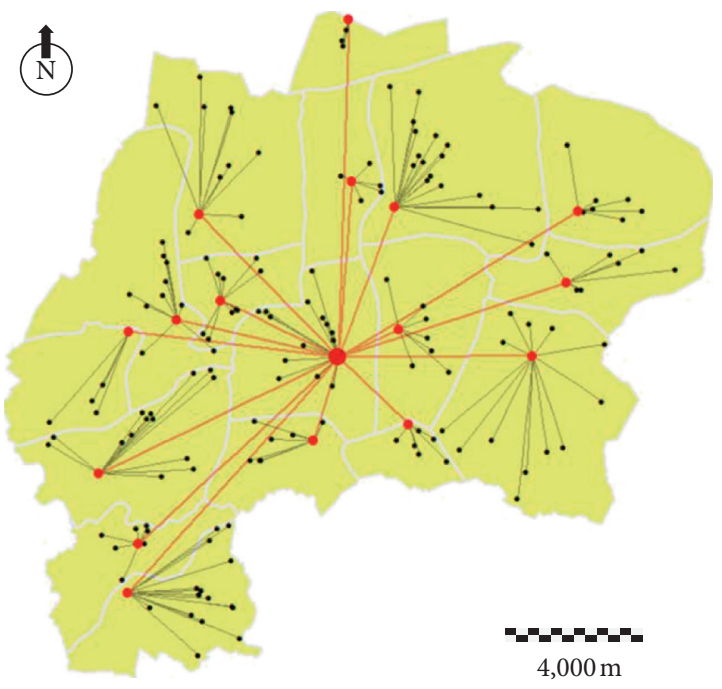

(d)

FIGURE 2: Implementation of the spatial network according to 2015 census data. (a) The most populated settlement for the whole study area is represented by a red node. This node is the central hub of the whole network. (b) A first-order network is established by linking this central hub with the most populated settlement in each parish. (c) A bunch of second-order networks is established by linking the most populated settlement in each parish with all the settlements within this same parish. (d) The final network results from merging the first-order and second-order spatial networks.

The historical population flows among settlements within our study area are shown in Section 4. There we compare population data for the whole network in two different years. The size of nodes represents the population in the most recent year. The hierarchy of links is based on the population data in the most recent year. The color of nodes refers to relative variations in the number of inhabitants between both years. We use a simple color legend where only three colors depict quantitative variations in the number of inhabitants for each node. Three additional colors are used for mapping the emergence or demise of any settlement in a concrete census year. In case of settlements not officially reported for one of the census years, these are represented, but not connected to the network. Finally, the color of nodes designates the color of links. In the case of a link connecting two differently colored nodes, it will show a color gradation between edges. To gain a detailed view, we present graphically this methodology in Figure 3.

\section{Results}

Our study area counted 9,635 inhabitants in 2015, 563 inhabitants more than in 1888. However, this growth was not constant over time. Data show two oppositional trends separated by a clear turning point in 1960 when this municipality peaked at 13,951 inhabitants (Figure 4). Since then, this municipality had lost nearly one-third of its population. The reason behind this is the collapse of traditional agrarian societies, which forced a large number of people to emigrate. Before the 1960s, most of these people migrated to South 


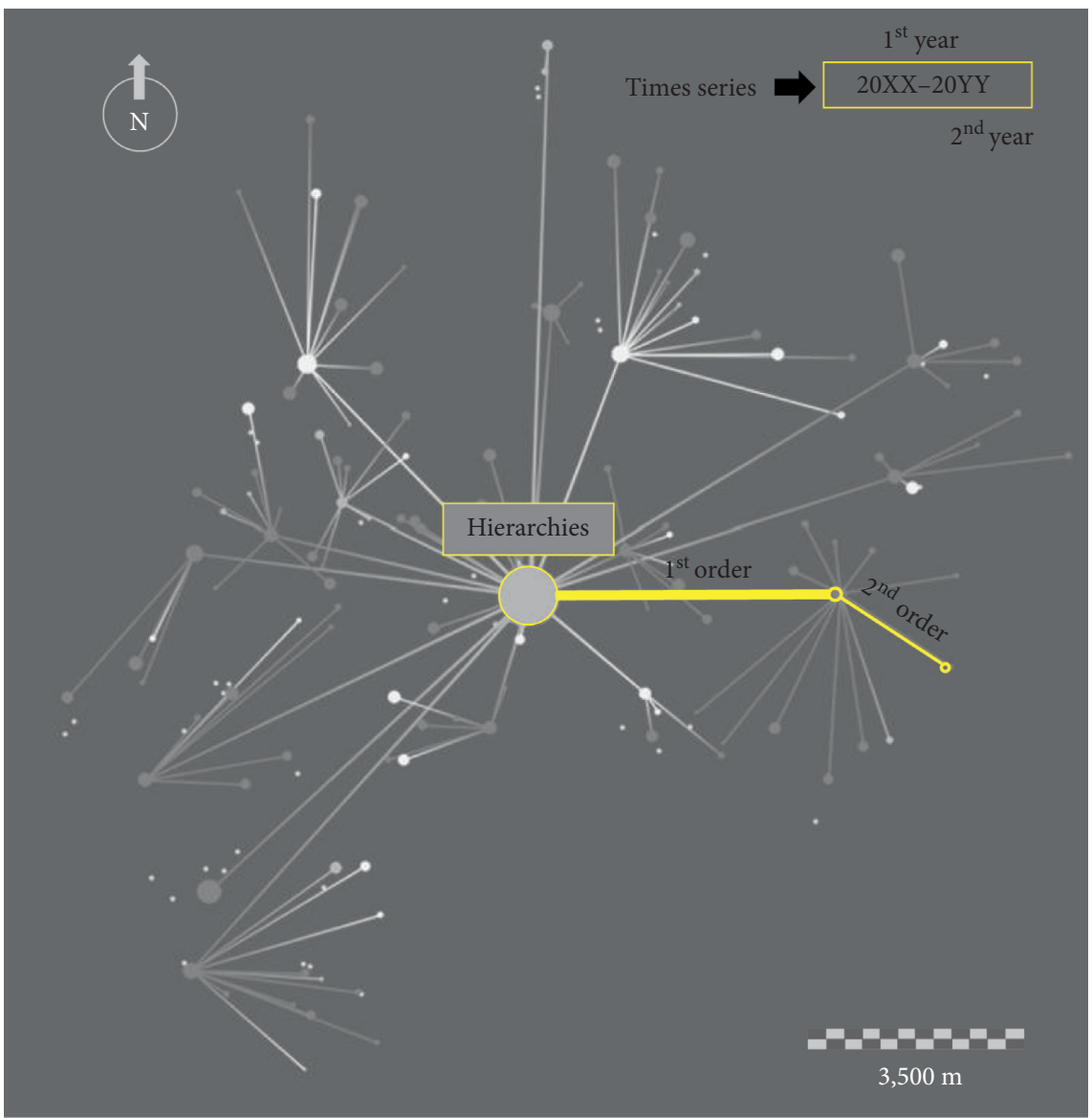

Node size

Node size is according to population in the $2^{\text {nd }}$ year, that is $20 \mathrm{YY}$

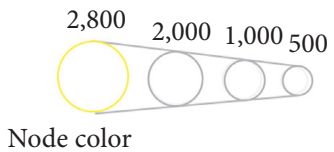

Node color is according to the relative difference of population between the $1^{\text {st }}(20 \mathrm{XX})$ and the $2^{\text {nd }}$ year $(20 \mathrm{YY})$

Population increases more than 5 percent

Population decreases more than 5 percent

Similar population (variation ranges between +5 and -5 percent)

Human settlement emerges in the most recent census year

Human settlement disappears in the most recent census year

Human settlement exists in none of both census years (but exists in any other census year)

Figure 3: Methodology for mapping population dynamics using spatial networks. This methodology is applied in Section 4.

American countries and later on there was a trend towards Central European countries. In the last decades, the majority of new migrants decided to move to the most important cities nearby [29].

A more comprehensive analysis of data allows us to observe important changes in the spatial pattern of population distribution. Figure 5 gives a synthetic view of an acute internal redistribution of the population at different scales over time. The size of boxes represents the relative population for all the parishes and settlements. Each minor box represents a single settlement. The aggregation of minor boxes with the same color refers to those which are part of the same parish. Three different years were considered: 1888 , 1960, and 2015. 1880 and 2015 correspond to the first and the last census years, respectively. The 1960 census is relevant because it is the peak and the turning point in the whole time series. The complete dataset for each year is organized hierarchically in these treemaps. Boxes sharing color are spatially distributed according to their areas. The minor boxes are located close to the bottom-right corner and the 


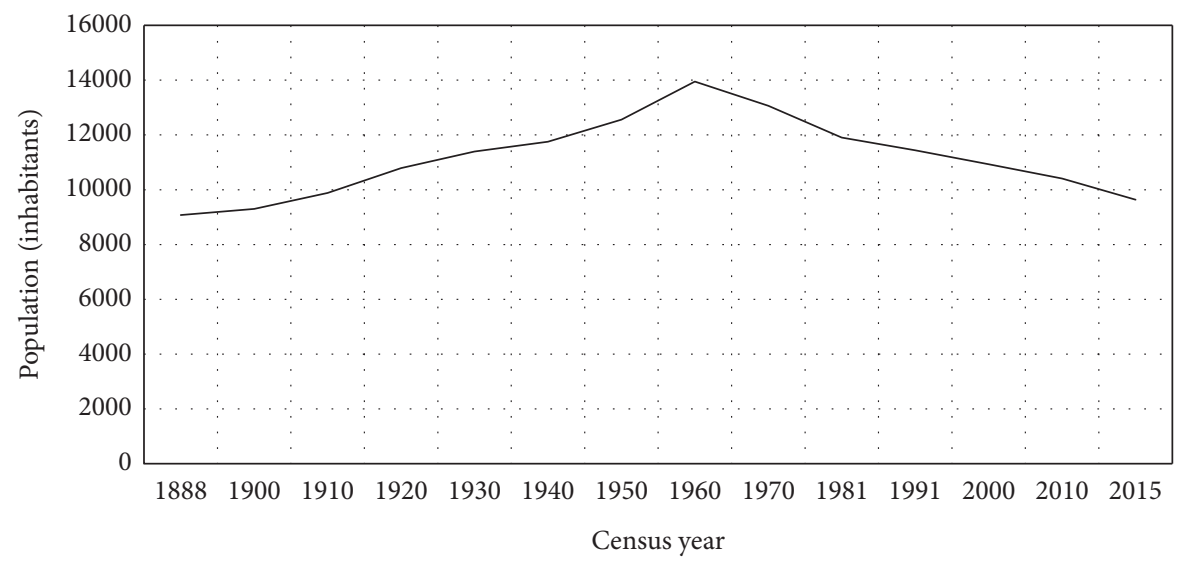

Figure 4: Population in the study area between 1888 and 2015.

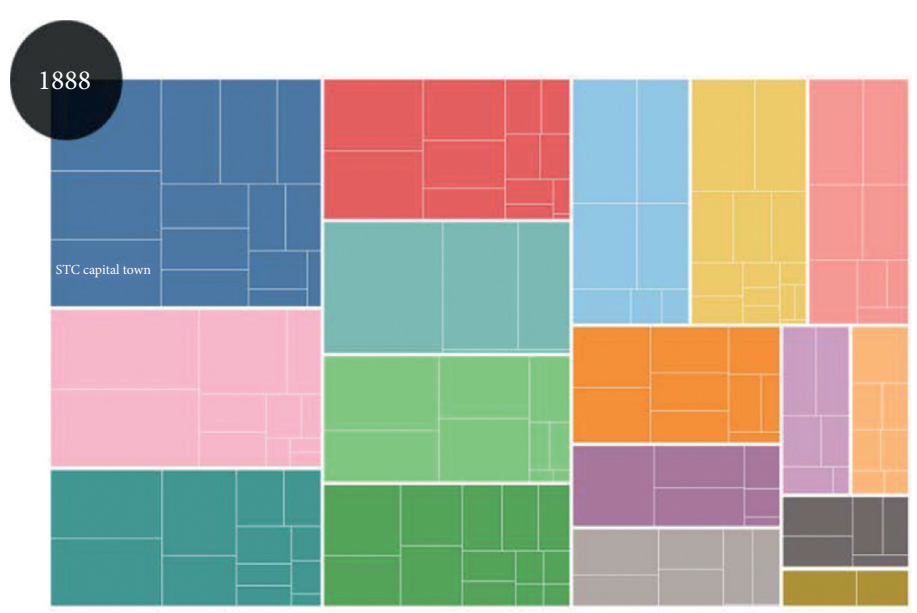

(a)
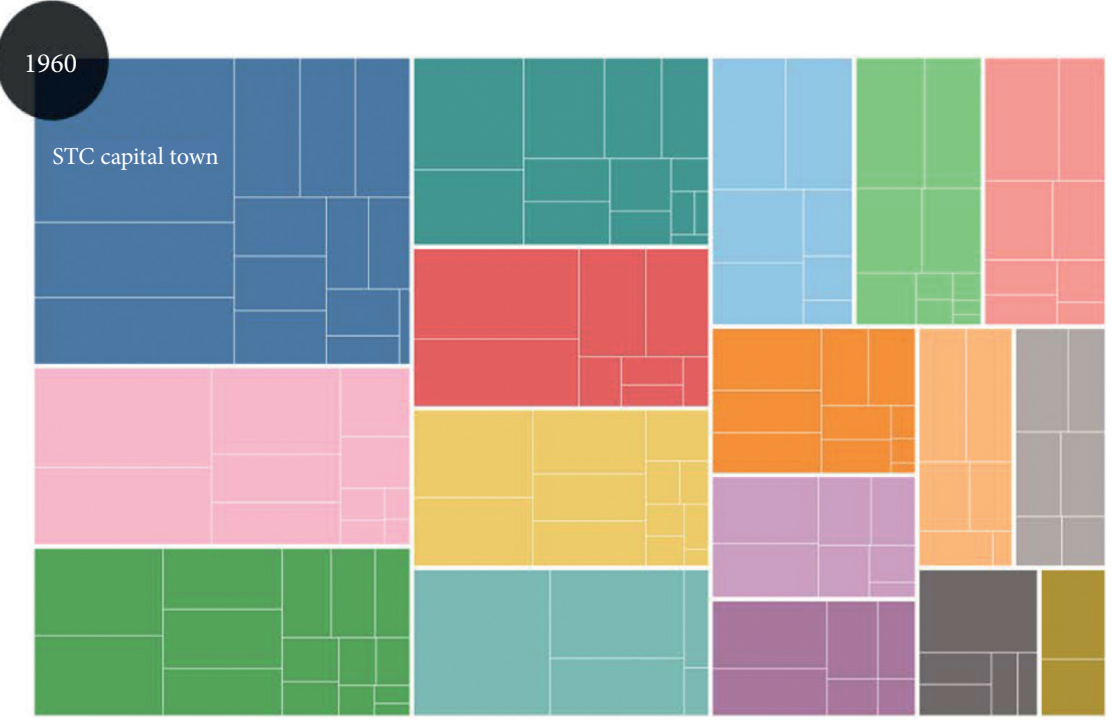

(b)

FIgURE 5: Continued. 


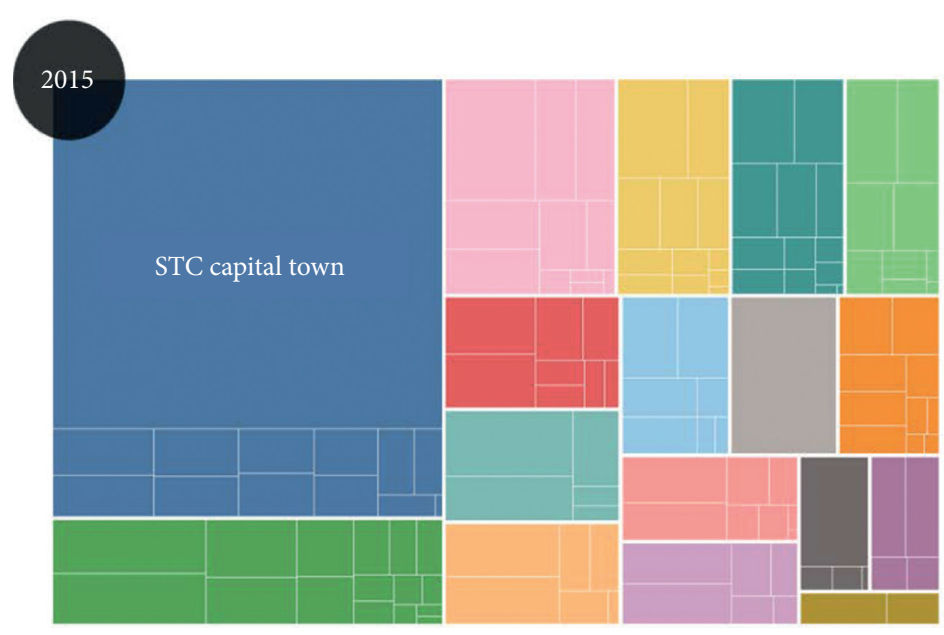

(c)

Figure 5: Cross-census comparison between (a) 1888, (b) 1960, and (c) 2015. The size of the complete chart for each year represents the total population in the whole municipality. Each settlement corresponds to a minor box, whose size depends on its relative population. The boxes with the same color are part of the same parish.

major ones close to the top-left corner. The color legend for the same parish is kept for all the years.

The most evident difference is the utmost importance of the capital town, whose box is labeled. According to data, it is the most populated node since 1940. In 1888, it was only the ninth most populated settlement in this municipality, with only 1.7 percent of the total population. In 2015, its population was 28.3 percent, a relative weight 16 times larger. In Figure 6, we represent the relative growth over time of the capital town in comparison to the rest of the municipality before and after 1960 and the time when the maximum population is reached.

As we can observe, both lines tend to diverge after 1960 . This means that the population is increasingly concentrated in one single node: the capital town. Although this node counted in 2015 with only 2,731 inhabitants, it can be equated to a child-size city. Thus, this capital town agglomerates a relevant number of urban activities that are proper central places such as business activities, commercial stores, public endowments, and office services, among others. Meanwhile, the rest of the settlements endures a growing crisis in terms of population.

Therefore, despite this study area being predominantly rural and thinly populated, we observe an acute internal redistribution of population. In this way, it demonstrates how urban dynamics result to be scale-independent, emerging even in thinly populated regions. In our study area, this is more evident after 1960, when the capital town only represented 4.7 percent of the total population. Half a century later, its population represents over six times more (28.3 percent), showing average growth rates of around 4 percent in relative terms in the last few decades (Figure 7).

A more comprehensive analysis for better understanding the actual population dynamics within this municipality is using spatial networks and fine-grained data over the whole time series. The following figures show a cross-census comparison for all the settlements officially reported. This is done using spatial networks, where nodes represent human settlements and links show hierarchies among nodes. The methodology for data mapping was previously introduced in Section 3.

Figure 8 shows the population dynamics for the periods running from 1888 to 1960 , and from 1960 to 2015. In the left figure, the spatial network presents a very balanced configuration related to their nodes. Many nodes presented a similar size and the green color was predominant. This means that the population was evenly distributed across the territory, in a face of population growth numbers. In the right figure, the main node adopts an extreme significance in terms of size and color. Thus, most of the network show negative population dynamics, which is the exact opposite of what is happening with the main node.

These same population dynamics are represented in Figure 9 for the periods in between successive censuses, which is around ten years for most of the cases. Among other important aspects, we can observe a clear and progressive variation of the predominant colors over time, shifting from mostly green to red tones in the most recent decades. Furthermore, some very significant modifications in the topology of the whole network are shown. The clearest change emerges after 1940 when the current capital town became the most populated node, which is located in the center of the whole network.

\section{Discussion}

Geographic science analyzes the relationships among natural and social systems by considering all their interdependences over the territory. Although many of these relationships were already addressed in the past, their spatial dynamics seem to be very diverse and complex. For this reason, it is strongly recommended to implement a multiscale approach for checking the spatial behavior of these dynamics at different spatial scales. The analytical geography proposes the 


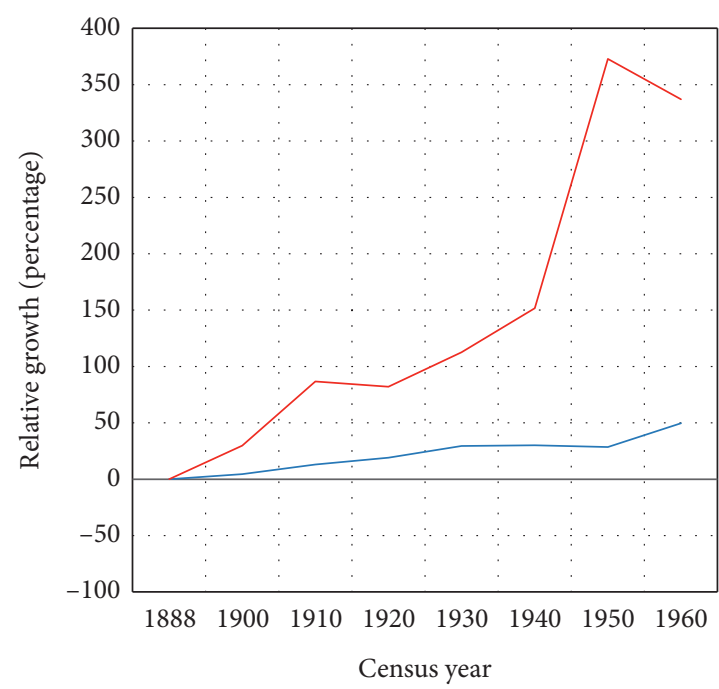

(a)

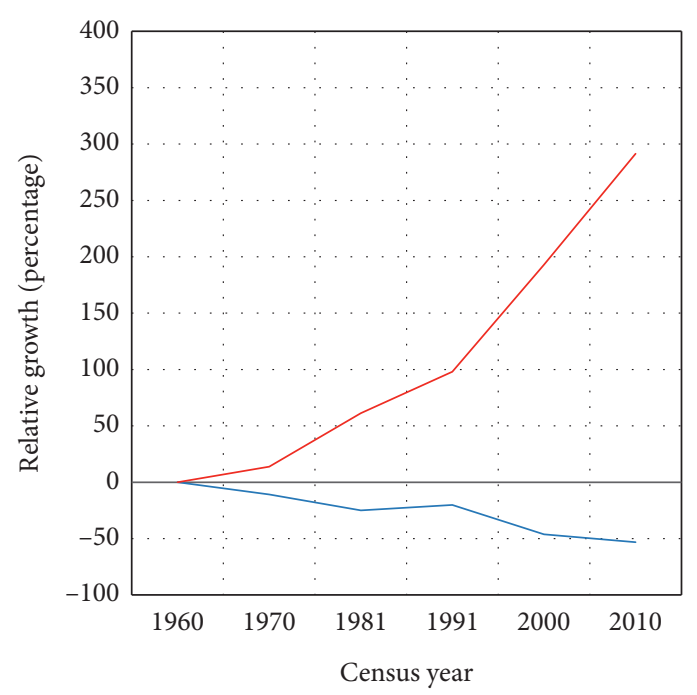

(b)

FIGURE 6: Relative growth of the capital town (red line) in comparison to the rest of the municipality excluding the capital town (blue line) before and after 1960 .

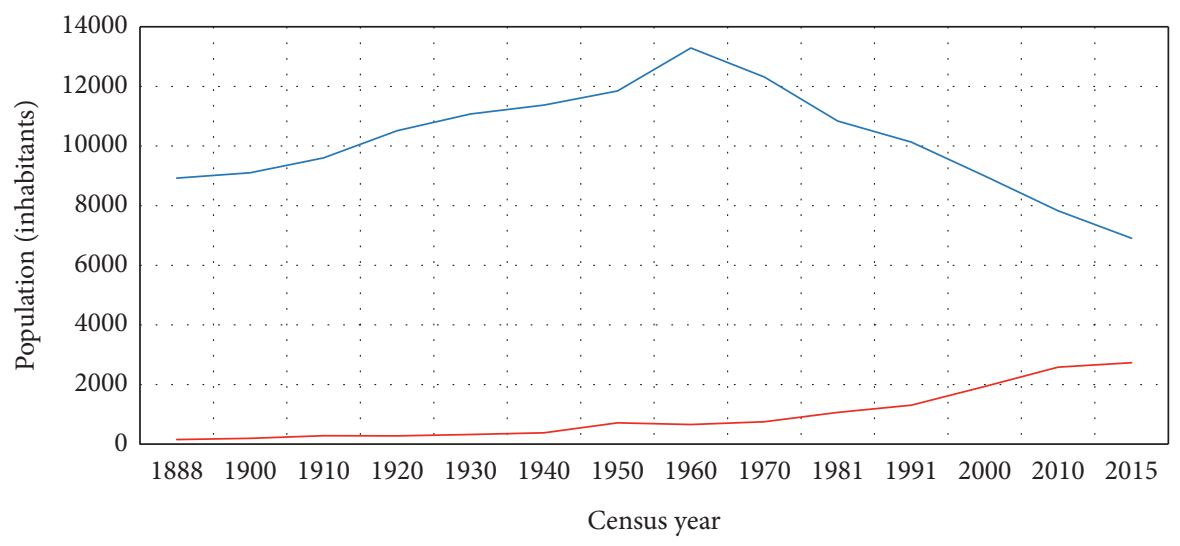

Figure 7: Population in the capital town (red line) and the whole municipality excluding the capital town (blue line) between 1888 and 2015.

use of cartographic models based on networks, flows, and graphs to measure this complexity across the territory.

In this paper, we show how dynamics only related to urban spaces emerge also in thinly populated regions. For years, dynamics related to urbanization were only analyzed in large cities and metropolises. However, these dynamics and related mechanisms do not only emerge in populated cities, but these are also evident in predominantly rural regions. Our study area is a good sample. In population terms, this area is facing a very regressive trend for the last half-century, losing nearly a third of the population. However, it has experienced a very acute process of internal redistribution of the population, where people have moved from the vast majority of rural settlements to the capital town. According to the spatial networks, the settlements located at the edges have reduced their importance, while the centrally located node is taking up more weight.

In broad terms, the segregation between urban and rural spaces is increasingly reinforced over time. Spatial networks show how this process is progressive, being the smallest nodes the first ones to disappear. It seems to be a factor more relevant than the geographical distance of nodes concerning the most populated town, which only counts with 2,731 inhabitants. However, this town has the power to attract people from the whole network, behaving like a child-size city at a local scale.

Depopulation in rural areas is more than a purely quantitative process. Beyond losing population, rural areas present increasingly weaker structures from a qualitative perspective. The young people of working ages are precisely the most expelled group, while elderly people are multiplying. This explains why rural areas experience a progressive weakening of their demographic structure and, in consequence, the population decline tends to be more severe over time.

The use of spatial networks for mapping population dynamics is very adequate for simplifying their complexity. This mapping strategy presents some advantages compared to choropleth maps, thanks to the structure based on nodes 


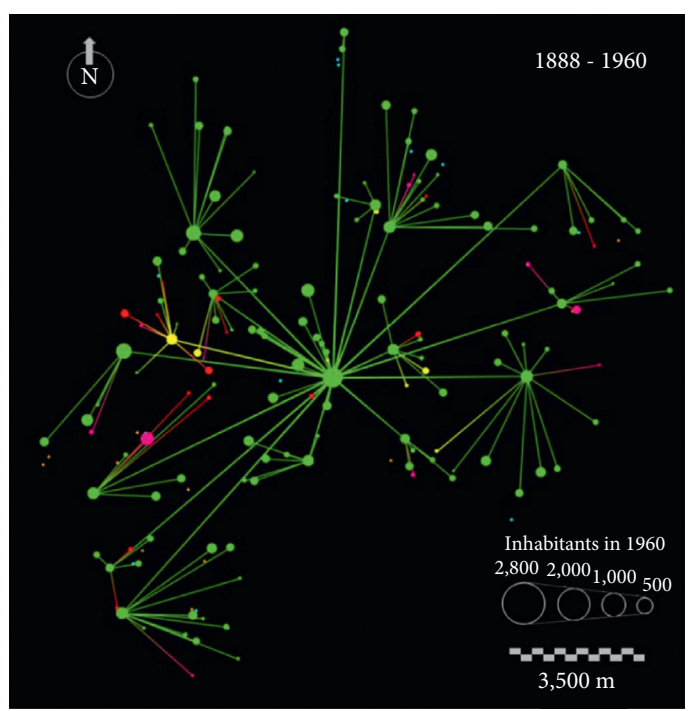

Node color

Period between the $1^{\text {st }}$ and the $2^{\text {nd }}$ census year

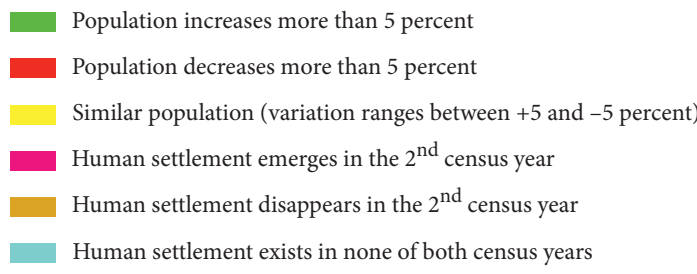

(a)

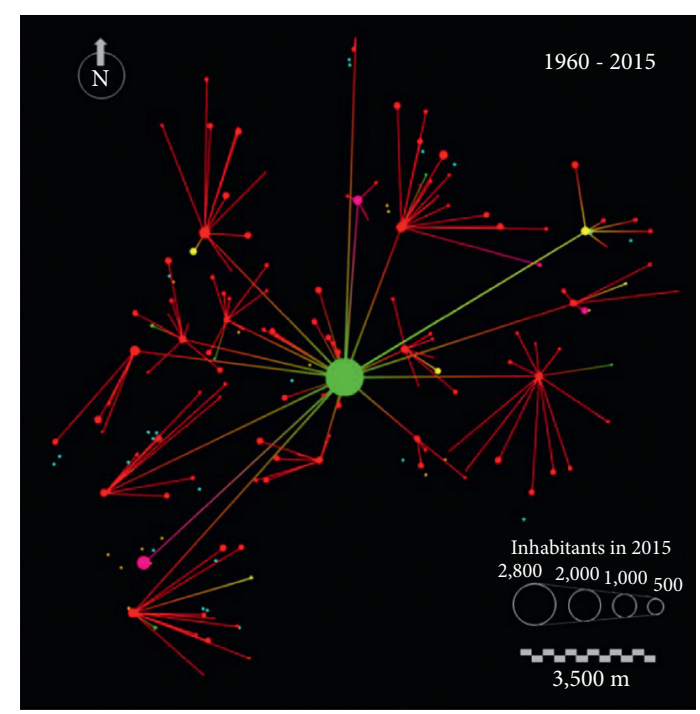

Node color

Period between the $1^{\text {st }}$ and the $2^{\text {nd }}$ census year

Population increases more than 5 percent

Population decreases more than 5 percent

Similar population (variation ranges between +5 and -5 percent)

Human settlement emerges in the $2^{\text {nd }}$ census year

Human settlement disappears in the $2^{\text {nd }}$ census year

Human settlement exists in none of both census years

(b)

Figure 8: Population change from 1888 to 1960 (left figure) and from 1960 to 2015 (right figure). Node size refers to the total population in the most recent year. Node color shows the relative variation between the first and the second year in each figure.

and links. We can represent not only fine-grained population data by nodes but also the changing hierarchies between nodes by links. It is important to note that links do not represent actual population flows in real-time, but these can be a proxy indicator. We also must emphasize that the spatial networks are not a closed system. Migration abroad was a very important factor for understanding the population dynamics in this municipality. Many people migrated to Brazil until 1960 and Central Europe afterward. Each of these migration flows presented its particularities. The migration to Brazil was mainly permanent with a great number of migrants that never returned. The migration to Central European countries was mainly temporary with most of these migrants returning after some years. However, most of them did not return to their hometowns but instead they settled down in the capital town where many of them opened new businesses. Their investments contributed decisively to the rapid growth of the capital town $[29,30]$.

We must carefully consider some limitations in this study. First, our study area belongs to a region with specific particularities from a demographic perspective. On the one hand, the spatial pattern of population distribution diverges substantially from the rest of Spain. In 2015, an average municipality in Spain counted with 5,716 inhabitants distributed in 7.6 settlements, whereas in Galicia it counted with 8,709 inhabitants distributed in 96.3 settlements. Therefore, an average settlement in Spain had approximately 752 inhabitants, eight times more population than one located in the region of Galicia [28]. The most outstanding aspect behind this spatial pattern is the fragmentation and dissemination of population across the region. Another relevant aspect refers to major changes in the topology in some of the spatial networks shown. In this study, the most significant change is visible after 1940 with the shift from an agrarian society to the prevailing one, dominated by an urban economy that is mostly concentrated in the capital town. Traditional economies in this region were based on small farms for family survival. The familiar structure counted with many children who were expected to contribute like major labor forces. Spatially, this demographic model was traditionally based on a balance between population and resources. In the event of any temporary imbalance, migration abroad turned into the main alternative for many families [31-33]. The transition to a new model was evident after the 1960s with the end of subsistence farming, the attraction of industrial cities, and the subsequent development of service-based economies. In our study area, the number of dwellers in the main node was exponentially increased since 1960 ( +313.8 percent). The capital town is nowadays the most important trading center for an extensive region beyond the administrative borders of this municipality. Also, the major changes in our spatial network, after 1940, show how the parish, a territorial figure with great relevance 


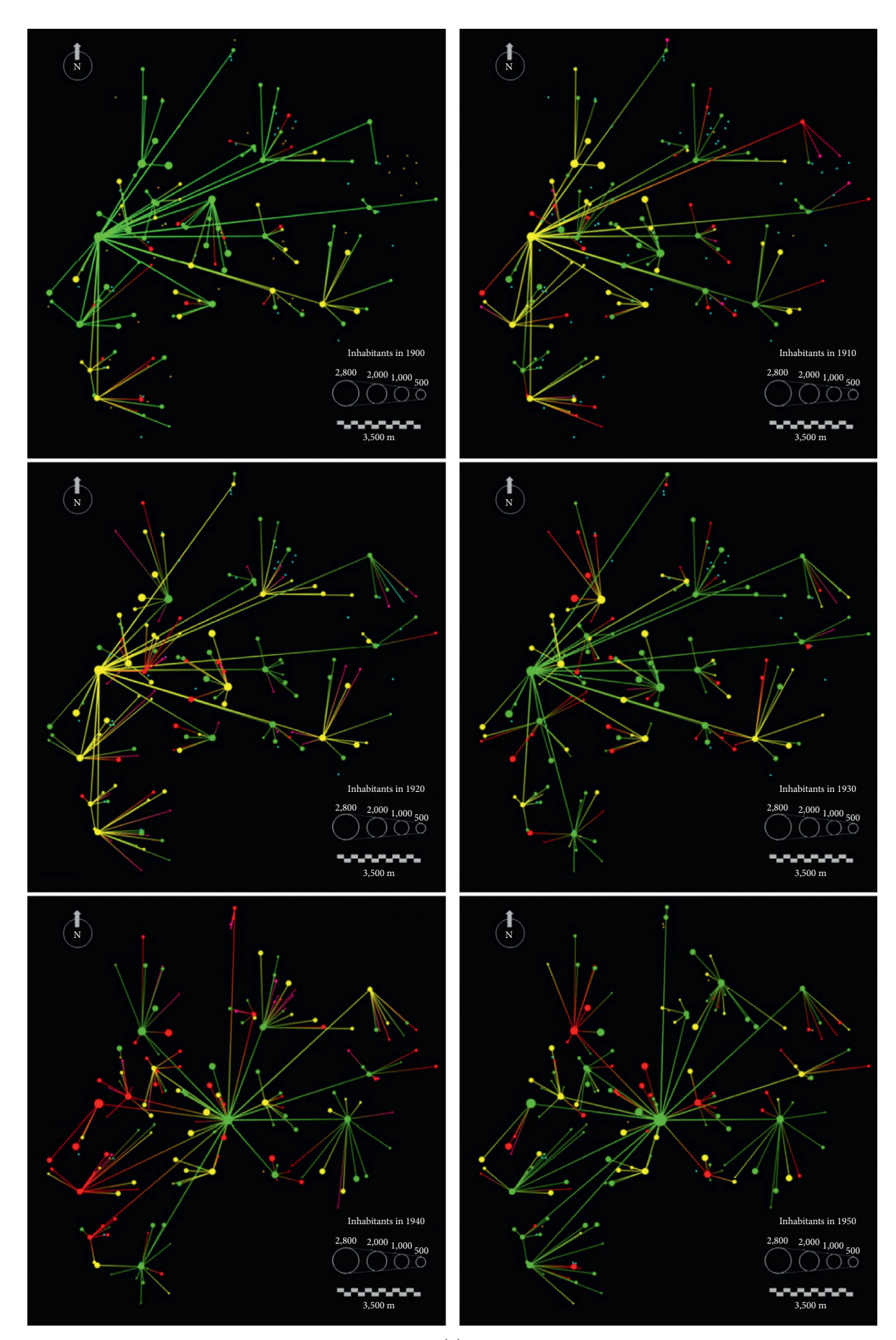




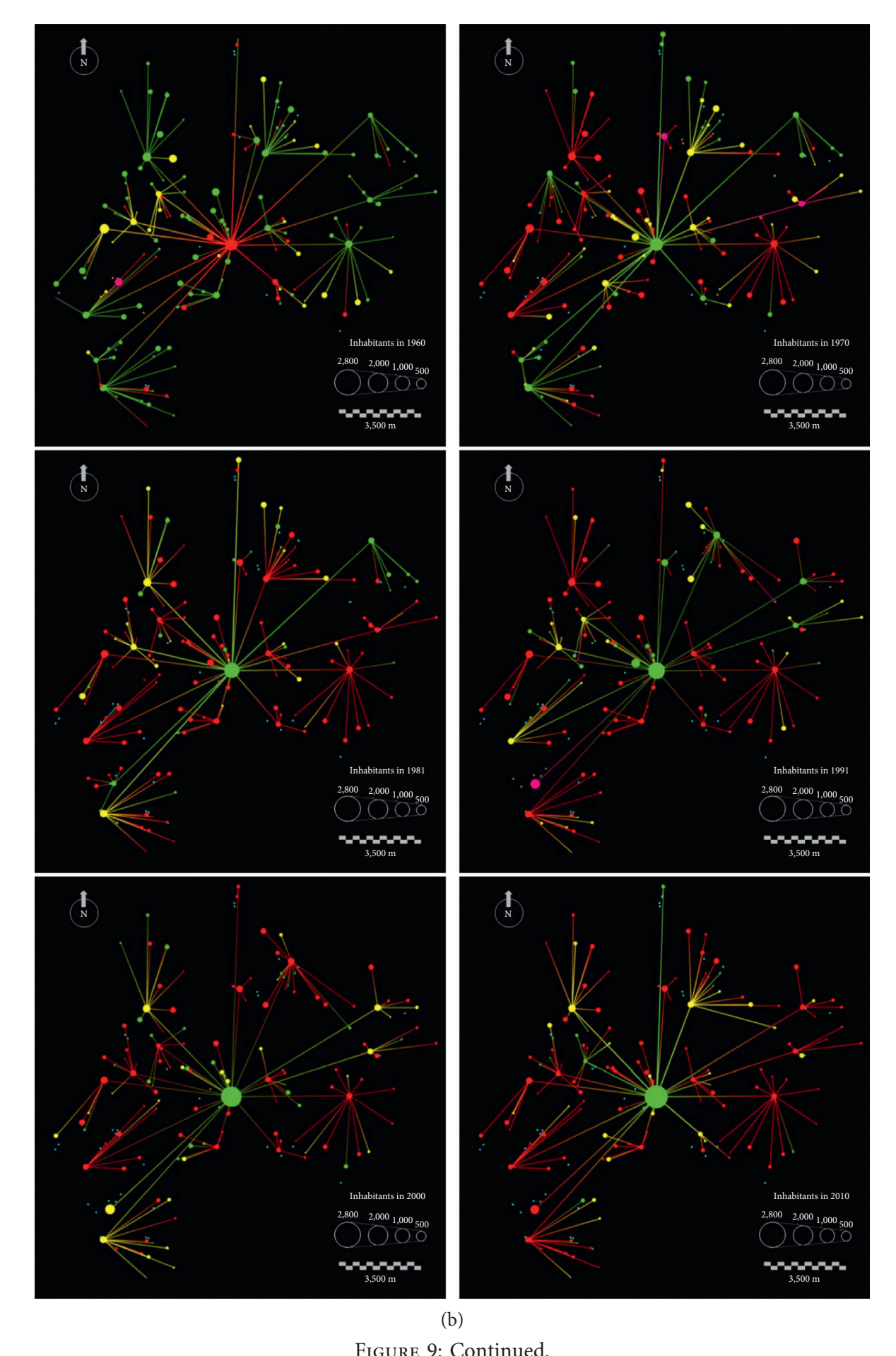



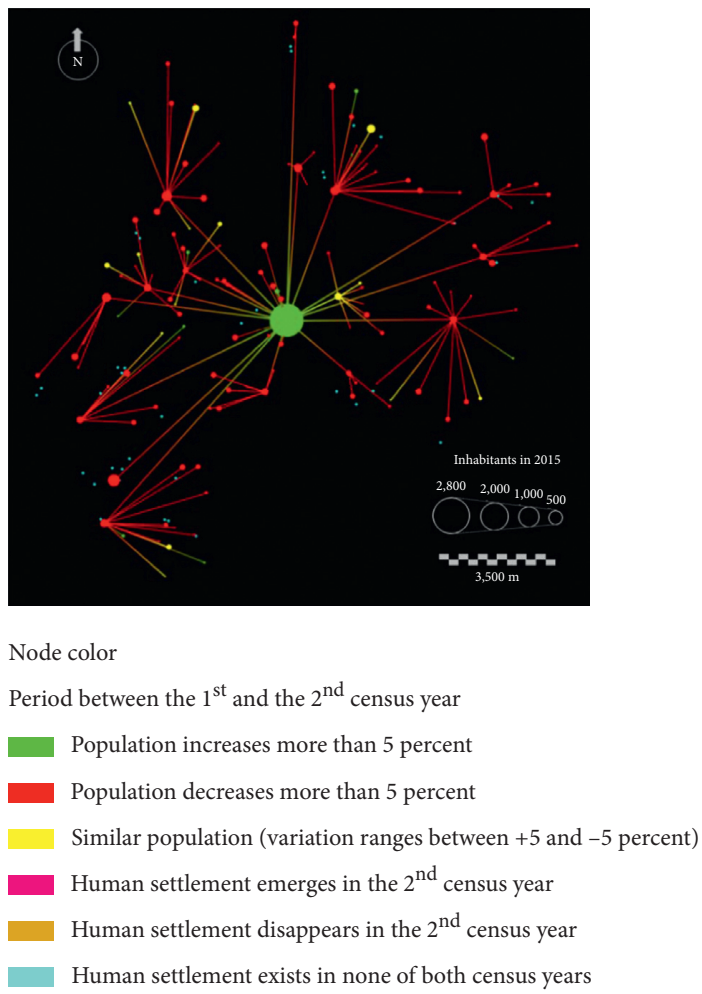

(c)

Figure 9: Population change for all the intercensal periods from 1888 to 2015. The period represented in each figure is shown in the upper right-hand corner. Node size refers to the total population in the most recent year. Node color shows the relative variation between the first and the second year in each figure. (a) 1888-1900, (b) 1900-1910, (c) 1910-1920, (d) 1920-1930, (e) 1930-1940, (f) 1940-1950, (g) 1950-1960, (h) 1960-1970, (i) 1970-1981, (j) 1981-1991, (k) 1991-2000, (l) 2000-2010, and (m) 2010-2015.

in the past, had lost most of its influence due to the secularization process and the decline of social power by the Church.

Another relevant aspect is the spatial relationship between population and resources nowadays. Population decline results in losing competitiveness and job positions, and vice versa. This creates a downward spiral for adopting unsustainable strategies for territorial management $[26,34]$. The ever-increasing concentration of people and wealth is leading to a distorted vision of the territory based on purely urban perspectives. It would explain why rural areas are increasingly under pressure, which is observed in forced changes of land uses in rural areas surrounding cities. According to the science of complex networks, those systems that concentrate an excessive number of interdependencies in a small group of nodes are more vulnerable by presenting more probabilities to fail $[35,36]$.

In response, policies for sustainable development must be encouraged to achieving a real convergence between urban and rural territories. This is particularly important in the context of the COVID-19 pandemic, which might lead to major changes in the spatial pattern of population distribution. In this sense, Kotkin [37] anticipates the end of the so-called megacities and the coming age of dispersion, with more people willing to live in less densely populated regions.

We have adopted a local-based approach in this study to verify the multiscalability of population dynamics. It is now crucial to adopt the right interventions to counterbalance the negative externalities. Small case studies like the one presented might be field trials for the actual implementation of policies and interventions. In this way, this can be an efficient way to assess the results and to optimize the costs.

In short, we have identified the presence of urban dynamics in areas rarely addressed in the mainstream literature on urban studies. Somehow, this paper lays the groundwork for future research aiming to deepen the understanding of urban dynamics at any spatial scale. Our findings can be extrapolated to other different regions across the world and these may contribute to adopting the right policies for promoting resilience in territorial management. Our findings are valuable for experts such as urban planners, policymakers, and other competent authorities with expertise in territorial management and spatial planning.

\section{Conclusions}

The objective of this paper is to demonstrate the multiscalar nature of certain urban dynamics. For this, we analyze population dynamics in a thinly populated region in decline for a long time series. Spatial networks are implemented to compare population data between two different years. The results show how only one of 175 nodes increases continuously its size, exactly the opposite of what occurs in the rest of the nodes. The process of concentration of population and 
the segregation between rural and urban spaces is visually displayed.

A recurrent downward spiral of depopulation and economic decline threatens the sustainability of the majority of rural regions. In response, policy-makers and experts must implement the right policies to adopt integrated territorial management without overemphasizing urban territories.

\section{Data Availability}

Population data used in this research are available at the Spanish Statistical Office website for the most recent decades. Historical data are only available from the corresponding author upon request.

\section{Conflicts of Interest}

The authors declare that they have no conflicts of interest.

\section{Acknowledgments}

The authors would like to thank Heike M. Grünsteudel for her contribution to review this paper.

\section{References}

[1] Department of Economic and Social Affairs, World Urbanization Prospects: 2018 Revision, Department of Economic and Social Affairs, UN Population Dynamics, New York, NY, USA, 2018.

[2] T. Misra, "Half the world's people live on 1 percent of its land," 2016, https://www.theatlantic.com/international/ archive/2016/01/world-population-distribution/422871/.

[3] M. Timberlake and J. Kentor, "Economic dependence, overurbanization, and economic growth: a study of less developed countries," The Sociological Quarterly, vol. 24, no. 4, pp. 489-507, 1983.

[4] P. Graves and R. Sexton, "Overurbanization and its relation to economic growth for less developed countries," Economy Forum, vol. 8, no. 1, pp. 95-100, 1979.

[5] D. H. Potts, "Whatever happened to Africa's rapid urbanization?" World Economics, vol. 13, no. 2, pp. 17-29, 2012.

[6] Y. Liu, Z. Li, and J. Jin, "Pseudo-urbanization or real urbanization? Urban China's emergence of administrative regions and its effects: a case study of Zhongshan city, Guangdong province," China Review, vol. 14, no. 1, pp. 37-59, 2014.

[7] S. Batishcheva, "World urbanization prospects and the problem of its infrastructural provision," Economic Analysis, vol. 46, no. 1-2, pp. 72-81, 2013.

[8] J. Balsa-Barreiro, Y. Li, A. Morales, and A. S. Pentland, "Globalization and the shifting centers of gravity of world's human dynamics: implications for sustainability," Journal of Cleaner Production, vol. 239, Article ID 117923, 2019.

[9] A. Pentland, Social Physics: How Social Networks Can Make Us Smarter, Penguin Books, New York, NY, USA, 2014

[10] I. S. Gill and C.-C. Goh, "Scale economies and cities," The World Bank Research Observer, vol. 25, no. 2, pp. 235-262, 2010.

[11] S. A. Frick and A. Rodríguez-Pose, "Change in urban concentration and economic growth," World Development, vol. 105, pp. 156-170, 2018a.
[12] R. Dobbs and J. Remes, "Trends. The shifting urban economic landscape: what does it mean for cities?" in Proceedings of the World Bank's Sixth Urban Research and Knowledge Symposium Washington, DC, USA, 2012.

[13] M. Chen, H. Zhang, W. Liu, and W. Zhang, "The global pattern of urbanization and economic growth: evidence from the last three decades," PLoS One, vol. 9, no. 8, Article ID e103799, 2014.

[14] World Bank, "Solid waste management," 2019, https://www. worldbank.org/en/topic/urbandevelopment/brief/solidwaste-management.

[15] S. A. Frick and A. Rodríguez-Pose, "Urban concentration and economic growth VOX CEPR Policy Portal,” 2018, https:// voxeu.org/article/urban-concentration-and-economicgrowth.

[16] O. Serpell, "Wrong about urbanization? How emerging factors could shift people away from cities," 2018, https:// kleinmanenergy.upenn.edu/policy-digests/wrong-abouturbanization.

[17] R. Florida, "The myth that urbanization means prosperity," 2017, https://www.theatlantic.com/business/archive/2017/12/ developing-world-city-size-urbanization/548468/.

[18] J. Balsa Barreiro and T. Hermosilla, "Socio-geographic analysis of the causes of the 2006's wildfires in Galicia (Spain)," Forest Systems, vol. 22, no. 3, pp. 497-509, 2013.

[19] A. Badía and M. Pallarés, "Spatial distribution of ignitions in Mediterranean periurban and rural areas: the case of Catalonia," International Journal of Wildland Fire, vol. 15, no. 2, pp. 187-196, 2006.

[20] Habitat III conference (2016): "The United Nations Conference on Housing and Sustainable Urban Development". Quito (Ecuador), http://habitat3.org.

[21] Spanish Statistical Office (INE), https://www.ine.es, 2019.

[22] F. J. Goerlich and I. Cantarino, "Estimaciones de la población rural y urbana a nivel municipal," Estadística Española, vol. 57, no. 186, pp. 5-28, 2015.

[23] E. Reig, F. J. Goerlich and, and I. Cantarino, Delimitación de áreas rurales y urbanas a nivel local. Demografía, coberturas de suelo y accesibilidad, Fundación BBVA, Bilbao, Spain, 2016.

[24] L. Dijkstra and H. Poelman, "A harmonised definition of cities and rural areas: the new degree of urbanisation," European Commission, Brussels, Belgique, 2014.

[25] F. Zoido and A. Arroyo, "La población de España," in Tendencias demográficas durante el siglo XX en España, Arroyo, Ed., pp. 17-75, Spanish Statistical Office, Madrid, Spain, 2003.

[26] J. Balsa-Barreiro, "Unsustainability of territorial models from a demographic point of view: the case of A Costa da Morte (Galicia, Spain)," Papeles de Población, vol. 19, no. 78, pp. 167-206, 2014.

[27] J. Balsa-Barreiro and S. Landsperger, "A Costa da Morte (Galicia, España): un modelo demográfico antagónico al español. Análisis de su evolución demográfica en el siglo XXI," Journal of Iberian and Latin American Research, vol. 21, no. 1, pp. 63-86, 2015.

[28] Spanish Statistical Office (INE), "Nomenclátor: población del Padrón Continuo por Unidad Poblacional," 2015, https:// www.ine.es/nomen2/index.do.

[29] J. Balsa Barreiro, "Evolución del urbanismo y de la disposición territorial del poblamiento en un municipio coruñés de interior: caso de Santa Comba (Galicia, España)," Revista de Urbanismo, vol. 24, pp. 76-118, 2011.

[30] J. C. Sánchez, "Bases para el análisis geohistórico del poblamiento rural tradicional en Galicia," Boletín de la Asociación de Geógrafos Españoles, vol. 62, pp. 75-99, 2013. 
[31] X. Martínez-Filgueira, D. Peón, and E. López-Iglesias, "Intrarural divides and regional planning: an analysis of a traditional emigration region (Galicia, Spain)," European Planning Studies, vol. 25, no. 7, pp. 1237-1255, 2017.

[32] S. Calvo-Iglesias, U. Fra-Paleo, and R. A. Diaz-Varela, "Changes in farming system and population as drivers of land cover and landscape dynamics: the case of enclosed and semiopenfield systems in Northern Galicia (Spain)," Landscape and Urban Planning, vol. 90, no. 3-4, pp. 168-177, 2009.

[33] A. Bouhier, "La Galice, essaigéographiqued'analysed'interpretation d'un vieuxcomplexeagraire," Ph.D. dissertation, University of Poitiers, La Roche-Sur-Yon, France, 1979.

[34] C. Jones, "The end of economic growth? Unintended consequences of a declining population," National Bureau of Economic Research, vol. 26651, 2020.

[35] J. Balsa-Barreiro, A. Vie, A. Morales, and M. Cebrian, "Deglobalization in a hyper-connected world," Palgrave Communications, vol. 6, p. 28, 2020.

[36] A. Vie and A. Morales, "How connected is too connected? Impact of network topology on systemic risk and collapse of complex economic systems," Computational Economics, vol. 15, 2020.

[37] J. Kotkin, “The coming age of dispersion," 2020, https:// quillette.com/2020/03/25/the-coming-age-of-dispersion/. 